\title{
OCULAR ALBINISM WITH CHANGES TYPICAL OF CARRIERS*
}

\author{
BY \\ VAGN OHRT \\ From the Department of Ophthalmology (Director: Prof. Viggo A. Jensen), \\ Municipal Hospital, University of Aarhus, Denmark
}

OCULAR albinism is a form of incomplete albinism in which the lack of pigment is chiefly confined to the eyes. The condition is relatively rare, but since it was described for the first time by Nettleship (1909), it has occasionally been demonstrated in various families. Nettleship was aware that the disease-producing gene was sex-linked, but assumed it to be recessive; recent investigations have since proved that the sex-linked gene of the condition is intermediate in its expression.

The ocular symptoms encountered in males with ocular albinism are also well known in generalized albinism. Affected individuals suffer from impaired vision and undulatory nystagmus; the retinae are poor in pigment; the choroidal vessels are seen with great clearness, and the macular areas are hypoplastic, lacking the yellow colour normally seen in red-free light (Vogt, 1924). The irides are bright and translucent, so that the pupils may appear faintly red. Strabismus and astigmatism are usually present. In addition, head nodding is often seen in early childhood.

Attention has been focused particularly on this complex of characteristic symptoms in males, whereas little interest has been taken in the apparently unaffected females.

However, Waardenburg (1947) was able to show, by the translucence of their irides, that these heterozygous females were carriers. A few years later, Falls (1951)'established what had been rendered likely by Waardenburg's observation, viz. that ocular albinism has an intermediate sex-linked mode of inheritance; he described a peculiar ophthalmoscopic picture which he had observed in all female carriers in two American families in which male members exhibited ocular albinism. Vogt (1941) had previously described these ophthalmoscopic changes in a female carrier, but it seems that he did not then realize the significance of his observation.

François and Deweer (1953) later described a large Belgian family of 179 members who exhibited exactly the same changes as those observed by Falls. 
I have personally had the opportunity to study a Danish family consisting of seven generations with 169 members, of whom I was able to examine 81 individuals representing four generations. Five males, including a pair of uniovular twins in whom the affection showed pronounced parallelism, revealed ocular albinism. In addition, unquestionable information of the disease was available in three men who had died. Of the females, fourteen exhibited the changes described by Falls (1951) as typical of carriers.

Ophthalmoscopically, the fundus of such a heterozygous female reveals normal pigmentation in the central area. The macula has retained its reflexes, but it is often denser and coarser in its pigmentation than normal. Peripherally, a peculiar polymorphous pattern of greyish-brown, irregular patches of granular pigmentation is seen. They begin centrally as faint granules, occasionally deposited as small rings; towards the periphery they increase in size, become more confluent, and map-like, with mainly radial orientation, and are separated by areas poor in pigment with clearly visible choroidal vessels.

\section{Method of Investigation}

Some of the patients were studied in the Department of Ophthalmology, but the majority had to be examined in their homes.

In addition to refraction, ophthalmoscopy, and diascleral transillumination, perimetry for white, red, and blue objects, and studies of colour sense and dark adaptation were performed in patients examined in the clinic.

In patients examined at home, the visual acuity was determined when conditions permitted this examination, the field of vision was tested by hand movements, but dark adaptation and colour sense were tested in only a few cases. One of the patients seen at home revealed a concentric contraction of the field due to excessive myopia, but the others had normal visual fields, colour sense, and dark adaptation, for which reason these tests are not mentioned in the descriptions of individual patients.

\section{JESSEN FAMILY}

The family originates from the Danish island of Samsö, on which a few members still live. It may be traced back as far as a woman (Generation I), who was married and had two sons (II, 1 and 2), of whom the elder (II, 1) suffered from ocular albinism, the disease still being present among his descendants. After the death of her husband, this woman had an illegitimate daughter (II, 3) who was evidently also a carrier since her son (III, 16) had the disease. As he had no daughters, the disease disappeared in this branch of the family. The affected members of the family (Fig. 1) are listed below.

Generation II (1).-According to the information available, the elder son of I had nystagmus, and his vision was so poor that his mother had to read his lessons aloud to him. A photograph suggests that he had strabismus, since one eye had been retouched by the photographer. Nothing is known as to the pigmentation of his hair and skin, and the photograph gives no information. 


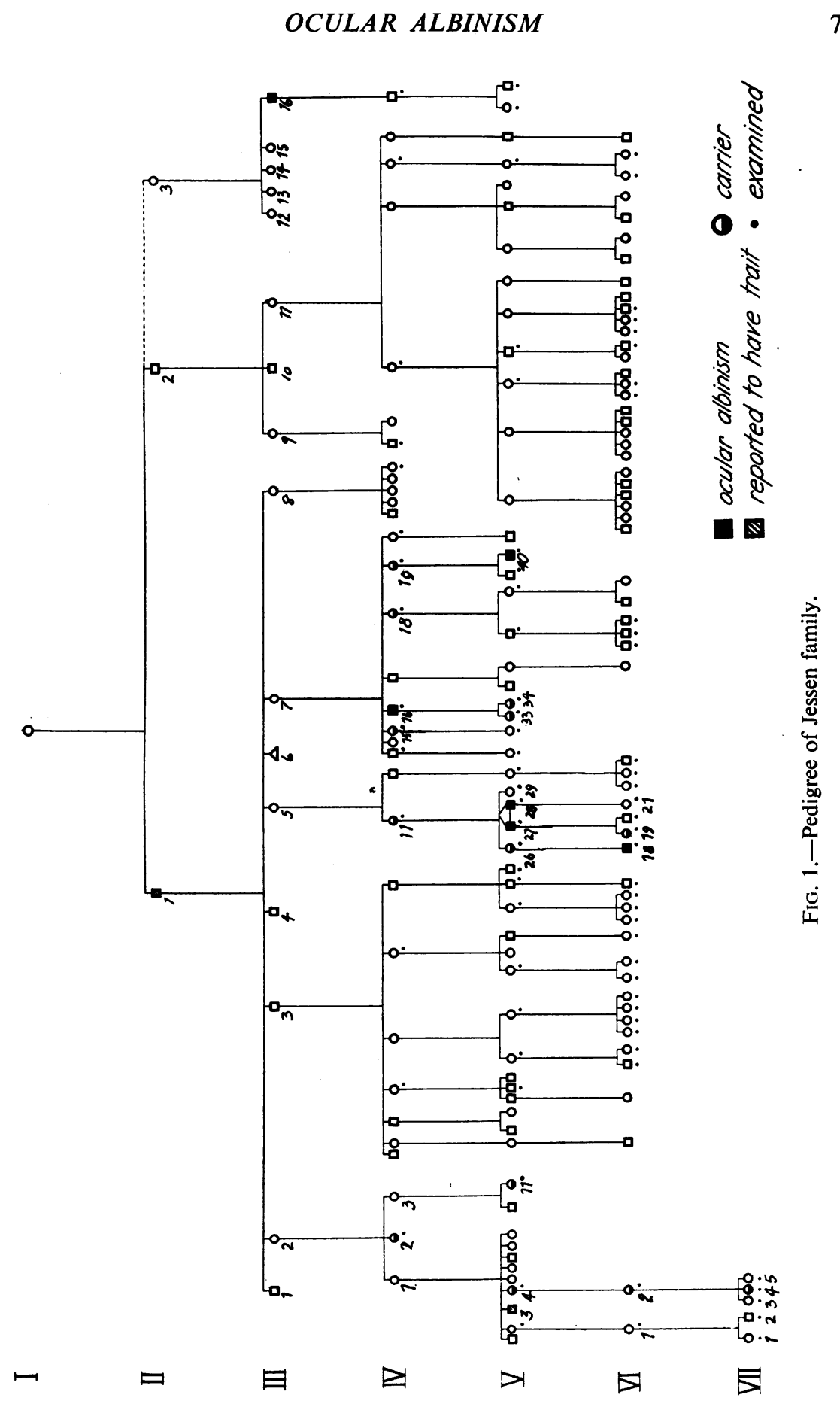


Generation III (16).-This man, son of II (3), who died at the age of 74, wase blonde with light blue eyes. He had nystagmus, convergent strabismus, and $\overline{\bar{z}}$ impaired vision, but he was able to read the newspaper when it was held close to his eyes. In addition, he had two white spots on the skin of the forehead and产 left temporal region.

Generation IV (2).-A woman aged 80, daughter of III (2), suffering from $\frac{\bar{c}}{\bar{c}}$ senile dementia, was examined in her home. Her hair had been dark, and the irides were greyish-brown. Ophthalmoscopical examination revealed changes with the fairly dark, closely aggregated patches of pigment typical of carriers.

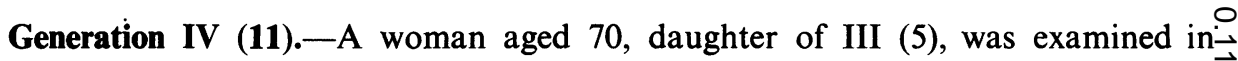
her home. She was medium fair with bluish-grey irides. Her family had occasion- $-\vec{\sigma}$ ally observed a fine nystagmus when she was tired.

The visual acuity in the right eye was $6 / 6+1 \mathrm{D} \mathrm{sph}$., and in the left $6 / 6+1 \cdot 5 \mathrm{D} \mathrm{sph}$

Ophthalmoscopy showed a typical carrier fundus, but the patches of pigment were smaller and more scattered, and the areas with sparse pigmentation were $\vec{v}$ larger than in the other carriers, though the appearance of the maculae was similar. Her four children and four grandchildren were all examined.

Generation V (26).-A woman aged 38, daughter of IV (11), was examined in herhome. As a child she had had very fair hair and did not react to sunburn. Now she was ash-blonde. The visual acuity in both eyes was 6/6-0.50D sph. A periodical, fine, undulatory nystagmus was noticed. The irides were blue, and diascleral trans- $-\frac{\mathcal{B}}{\square}$ illumination showed pronounced translucency. The ophthalmoscopic picture was similar to that seen in the mother (IV, 11).

Generation VI (18).-A boy aged 4, son of V (26), was examined in his home. ज़ colour of his hair and skin was very light. The visual acuity of the right eye was appr. $3 / 18+2 \mathrm{D}$ sph., $+2 \mathrm{D}$ cyl. at $90^{\circ}$, and in the left eye approx. $3 / 9+2 \cdot 5 \mathrm{D}$ sph., $+2 \mathrm{D}$ cyl.o at $90^{\circ}$.

A constant coarse, horizontal nystagmus with a somewhat varying amplitude and con siderable convergent strabismus of the right eye were observed. The irides were light andڤ్ translucent, and a faint red reflex from the pupils was seen. Ophthalmoscopy showed a@ typical albinotic fundus.

Generation V (27) and (28).- Two men aged 35, sons of IV (11) and identical twins, were examined in their homes. In childhood, they had had almost white hair and very light skin and did not react to sunburn; some photophobia and head nodding. had been present. In adult life they were ash-blonde and could, to some extent, be tanned by the sun.

In V (27) the visual acuity in both eyes was slightly less than $6 / 24 A 2.5 \mathrm{D}$ cyl. at $90^{\circ} \mathrm{C}$ There was a coarse, undulatory horizontal nystagmus, which was aggravated when heg became nervous or was called upon to fix his gaze on certain objects. The irides were light blue and markedly translucent, and the pupils appeared faintly red. Ophthalmo-o scopy revealed a typical albinotic eyeground.

In $V(28)$ the visual acuity in the right eye was slightly less than $6 / 24+1 \mathrm{D}$ sph., $+1 \cdot 5 \mathrm{D}$ cyl. at $105^{\circ}$; in the left eye it was slightly less than $6 / 24+1 \mathrm{D}$ sph., $+1 \mathrm{D}$ cyl. at $120^{\circ}$. A slight divergent strabismus of the left eye was present. Otherwise, theo conditions were exactly like those observed in his brother.

Generation VI (19).-A girl aged 10, daughter of V (27), was examined in her home. Her hair was medium blonde. The visual acuity in both eyes was $6 / 6$, emmetropia. Theo irides were blue and distinctly translucent. Ophthalmoscopy revealed typical carrieto changes. 
Generation V (29).- - This woman, daughter of IV (11), the youngest of four siblings, was the only one who had always had dark hair. She was examined in her home. The visual acuity in the right eye was $6 / 6$, and in the left eye $6 / 9$ with her own correcting glasses (sph.). The irides were darkish-blue and distinctly translucent. Ophthalmoscopy showed typical carrier changes. The patches of pigment were dark and closely aggregated (Fig. 2).

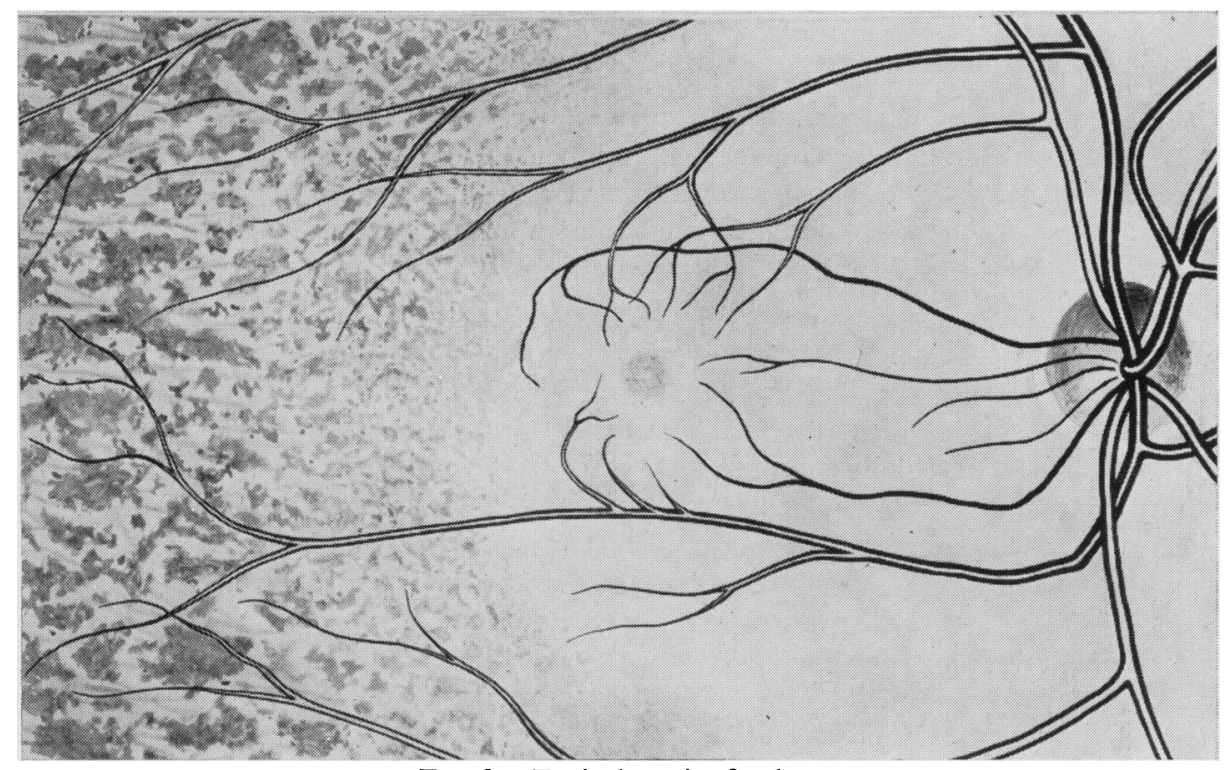

Fig. 2.-Typical carrier fundus.

Generation IV (15).-A dark-haired woman aged 63, daughter of III (7), was examined in the Department of Ophthalmology. The visual acuity in the right eye was $6 / 9+1 \cdot 5 \mathrm{D}$ sph., $+3 \mathrm{D}$ cyl. at $125^{\circ}$; and in the left eye $6 / 9+1 \mathrm{D}$ sph., $+3 \mathrm{D}$ cyl. at $90^{\circ}$. The irides were darkish-blue without translucence. There was a slight alternating divergent strabismus. Ophthalmoscopy showed typical carrier changes, with closely aggregated patches of pigment, which seemed to be somewhat darker than in her blonder sisters.

Generation IV (16). - A man aged 60, son of III (7), was examined in his home. In childhood, he had been almost white-haired with a fair complexion; he had not suffered from head nodding; later in life his hair and skin became a little darker. The visual acuity in the right eye was counting fingers at $0.5 \mathrm{~m}$. and in the left eye it was 6/60-10D sph.; no improvement with cylindrical glasses. (In 1937, astigmometry had shown: right eye $\pm 3 \mathrm{D}$ cyl. at $0^{\circ}$; left eye $\pm 3 \mathrm{D}$ cyl. at $15^{\circ}$.) There was coarse, highly variable, horizontal, undulatory nystagmus. A mixed convergent and sursumvergent strabismus was present. The irides were light and markedly translucent. Ophthalmoscopy revealed typical albinotic retinae with pronounced depigmentation and myopic degenerative changes. Determination of the visual field by hand movements showed some concentric contraction in both eyes.

Generation V (33).-A medium-blonde woman aged 31, daughter of IV (16), was examined in the Department of Ophthalmology. The visual acuity in the right eye 
was $6 / 12+1 \cdot 5 \mathrm{D}$ sph., $+2 \mathrm{D}$ cyl. at $70^{\circ}$, and in the left eye $6 / 6+0.5 \mathrm{D}$ sph., $+0 \cdot 5 \mathrm{D}$ cyl. at $145^{\circ}$. The right eye showed slight convergent strabismus. The irides were blue and translucent. Ophthalmoscopy showed typical carrier changes.

Generation V (34). - A medium-blonde woman aged 28, daughter of IV (15), was examined in the Department of Ophthalmology. The visual acuity in the right eyes was $6 / 24$, no improvement with glasses; and in the left eye $6 / 6+0.5 \mathrm{D}$ cyl. at $90^{\circ}$ 을 There was no strabismus. The irides were blue and translucent. Ophthalmoscopyo showed typical carrier changes.

Generation IV (18). - A woman aged 55, daughter of III (7), was examined in尺 the Department of Ophthalmology. In childhood she had been very fair, butes was now ash-blonde. In the right inguinal region she had a large depigmente 5 spot, but otherwise the skin showed normal pigmentation. The visual acuity inthe right eye was $6 / 6+2 \mathrm{D}$ sph., and in the left eye $6 / 12+1 \cdot 25 \mathrm{D}$ sph., $+0 \cdot 5 \mathrm{D}$ cyl $\vec{\sigma}$ at $110^{\circ}$. The irides were blue and translucent. Ophthalmoscopy showed typica $\overline{\mathrm{S}} \mathrm{O}$. carrier changes.

Generation IV (19).-A woman aged 52, daughter of III (7), was examined in the Department of Ophthalmology. In childhood she had been very fair, but was now ash-blonde. The visual acuity in both eyes was $6 / 12+5 \mathrm{D}$ sph., +3D cyl. at $90^{\circ}$. There was slight convergent strabismus of the left eye. A fineg undulatory nystagmus was occasionally present. The irides were blue and translucent. Ophthalmoscopy showed typical carrier changes; the appearance of the maculae did not deviate from that in the other carriers. The younger of her twoô sons suffered from ocular albinism:

Generation V (40). - A boy aged 12 years, son of IV (19), was examined in the Department of Ophthalmology. His vision had been impaired from birth. Durioggeo the first years of life he had been almost white-haired, and some head nodding hag been noticed. Now he was blonde. The visual acuity in the right eye was 6/60 + sph., $+3 \mathrm{D}$ cyl. at $90^{\circ}$, and in the left eye $6 / 60+4 \mathrm{D}$ sph., $+3 \mathrm{D}$ cyl. at $90^{\circ}$. A constanto coarse, undulatory, horizontal nystagmus with a somewhat varying amplitude wass present. The irides were light blue and translucent. Ophthalmoscopy showed typical albinotic fundus.

Generation V (3). - This boy, son of IV (1) and nephew of IV (2), had died at the age of 14 years. His parents were very dark, and the boy had had dark haing and brown eyes. His vision had been poor, and he had suffered from a pronounced nystagmus and divergent strabismus.

Generation V (4).-A woman aged 54, daughter of IV (1) and niece of IV (2) was examined in the Department of Ophthalmology. Her hair was bleached, but: the natural colour was stated to be medium-blonde. In childhood she had been? blonde, but not strikingly fair. The visual acuity in both eyes was $6 / 6+0 \cdot 5 \mathrm{D}$ sph The irides were blue and translucent. Ophthalmoscopy showed typical carrier? changes.

Generation VI (2).-A dark-haired woman aged 27, daughter of V (4), was examined in the Department of Ophthalmology. The visual acuity in both eyes was $6 / 6+0 \cdot 5 \mathrm{D}$. sph. The irides were darkish-blue and translucent. Ophthalmoscopy showed typical carrier changes with dark and closely aggregated patches of pigment. The second of her three daughters who were examined at home proved to be a carrier:

Generation VII (4).-A girl aged 5 years, daughter of V (4), had chestnut-coloured hair, which had never been lighter. The irides were blue and translucent. Ophthalmoscopyo showed typical carrier changes. 
Generation V (11).-This woman, daughter of IV (3) and niece of IV (2), had always had dark hair. She exhibited heterochromia, the right iris being light brown, the left bluish-grey. In addition, she had a small, sharply-defined area of depigmentation in the jugular fossa; otherwise the skin showed normal pigmentation. The visual acuity in the right eye was $6 / 6-1 \mathrm{D}$ cyl. at $175^{\circ}$, and in the left eye 6/6-0.5D cyl. at $5^{\circ}$. The irides were not translucent. Ophthalmoscopy showed typical carrier changes, with rather dark patches of pigment.

\section{Discussion}

The ophthalmoscopic picture observed in the fourteen carriers was characteristic and easily recognizable, but varied with regard to the intensity of the pigmented patches and the relation between the areas with heavy and sparse pigmentation. However, two individuals differed to some extent from the others, viz. the mother of the affected identical twins and the elder of her two daughters, who were both heterozygous. In these two women the retinal areas with sparse pigmentation were larger and the patches of pigment smaller and weaker than in the others, and thus, although typical of carrier fundi, more like the retinae of the affected males. In the other carriers the variations were small, but it seemed to be the rule that in individuals with dark skin and hair the patches of pigment were somewhat denser and darker than in those with hair and skin of a lighter colour.

Other findings of interest were revealed in these carriers. The mother and her daughter had a periodical, fine undulatory nystagmus, rarely present in the darker mother but frequently seen in her blonde daughter. Another blonde heterozygous woman had a similar nystagmus. This woman suffered from visual impairment in both eyes (6/12), fairly pronounced nystagmus, and slight convergent strabismus. Her darker sister had astigmatism of almost the same intensity, a similar strabismus, but a visual acuity of 6/9 in both eyes and no nystagmus. Astigmatism and strabismus were also present in other carriers; in one case together, in the others isolated.

Of eleven carriers studied for translucency of the irides, nine exhibited the symptom, but it was absent in two dark-haired women.

In the first place, these findings show that female carriers may exhibit abortive symptoms of ocular albinism other than the ophthalmoscopic changes, which are constantly present, and the translucence of the irides, which is usually but not invariably present.

Secondly, the investigation shows that there must be a considerable variation in the expressivity of the intermediate gene. Previous investigations may be interpreted in the same direction. Thus, for example, François and Deweer (1953) state that three of an affected man's five daughters had normal fundi, but as neither this nor previous studies leave doubt as to a sex-linked mode of inheritance, these three women must have been carriers and the expressivity of the gene must, accordingly, have been very weak. 
The same was the case with one of the patients described by Falls (1951), a one-eyed man with very mild ocular albinism; the visual acuity was norma and the fundus revealed patches of pigment similar to those seen in hetero은 zygous women.

When, in the literature on this disorder, information is given as to the general pigmentation of the affected males, these individuals are usuallyo described as blonde or white-haired, with a fair complexion. This suggest that the responsible gene has a wider effect and, as emphasized by Sorsby (1951), may produce mild manifestations of generalized albinism. In thes family I studied, information was available as to the general pigmentation $\vec{p}$ in seven out of eight males. Of these, six were blonde, and in childhood they had had almost white hair and had not reacted to sunburn. The pigmentation increased with age; although they remained blonde in adulti. life, they were not strikingly fair, and they were able to be tanned by the sun to some extent. One of the deceased males with unquestionable impair $\vec{\sim}$ ment of vision and nystagmus was dark and was the son of very dark parentsiv This variation should presumably also be seen against the background of the expressivity of the gene.

The general pigmentation varied within wide limits in the carriers. Onp the whole, most abortive symptoms were present in the blondes and seemec often most pronounced in them, though those with dark hair were also ${ }_{5}^{3}$ sometimes considerably affected. It is reasonable to assume that the gene is also able to exert a certain, although weak, influence on the gene $\overrightarrow{0}$ pigmentation in carriers.

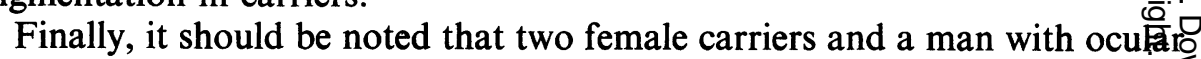
albinism also had cutaneous areas of depigmentation and one woman had heterochromia. That these changes should be due to the same gene asi that responsible for the ocular affection is, however, unlikely, since a healthy son of an affected man also showed an area of sparse cutaneous pigmentation and a woman who was not a carrier had a lock of white hair.

The conclusion must be that the sex-linked intermediate gene which is responsible for ocular albinism varies considerably in expressivity, and has a weak influence on the general pigmentation as well as its principal effect on the eyes.

\section{Summary}

In a family consisting of 169 members, eight men including a pair of identical twins suffered from ocular albinism. Fundus changes characteristic of carriers were seen in fourteen females of the family. In addition to the ophthalmoscopical changes and translucence of the irides, some of the female carriers exhibited other abortive symptoms of ocular albinism N It is demonstrated that the intermediate sex-linked gene shows considerable variation in its expressivity, and the study confirms that this gene has as 
weak influence on the general pigmentation as well as its principal effect on the eyes.

\section{REFERENCES}

Falls, H. F. (1951). Amer. J. Ophthal., 34, No. 5, pt. 2, p. 41.

FrançoIs. J., and DewEer, J. P. (1953). Ophthalmologica (Basel), 126, 209.

NeTTLESHIP, E. (1909). Trans. ophthal. Soc. U.K., 29, p. cxxiii (Bowman Lecture).

SORSBY, A., (1951). "Genetics in Ophthalmology", p. 203. Butterworth, London.

VoGt, A. (1924). Klin. Mbl. Augenheilk., 72, 806.

(1941). "Handbook and Atlas of the Slit-Lamp Microscopy of the Living Eye", pp. 844847. Schweizer Druck-und Verlagshaus, Zürich.

WaArdenburg, P. J. (1947). Ned. T. Geneesk., 91, 1863. 